\title{
Экспертная оценка социально-психологической компетентности подростков с отклонениями в развитии
}

\section{Юлия А. Королева}

Оренбургский государственный педагогический университет, г. Оренбург, Российская Федерация

*E-mail: koroleva-y@yandex.ru

\begin{abstract}
Аннотация
Ввеление. Автором Аоказывается актуальность изучения социально-психологической компетентности (СПК), обеспечивающей эффрективность субъект-субъектного взаимодействия. Повышение требований современного общества к умениям и навыкам межличностного взаимодействия и снижение способности к взаимоАействию у поАростков с разными вариантами откАонений в развитии позволяют считать настоящее исследование актуальным и перспективным.

Новизна исследования заключается в разработке авторской метолики, позволяющей целостно изучить специфику социально-психологической компетентности, и в проведении компаративного экспериментального исслеАования компетентности у поАростков С нормативным развитием и полростков с различными вариантами отклонений в развитии: с умственной отсталостью, с нарушением зрения и с нарушением слуха.
\end{abstract}

Методы. В разделе описываются критерии к определению выборки и ее характеристики, а также обосновываются Аостоинства использованного в исслеАовании метоАа экспертной оценки Аля изучения Аичностных конструктов у поАростков с отклонениями в развитии.

Результаты. В Аанном разделе представляется содержание авторской метолики, поэтапно описывается процедура ее разработки, вк^ючая определение належности отАельных шкал и всей методики, нормирование результатов по шкалам Аля вылеления уровней. Автором приводятся результаты экспертного оценивания социально-психологической компетентности поАростков, позволяющие поАтвержАать, что интемлектуальные возможности лиц с сенсорными нарушениями обеспечивают условия Аля развития у них способности к взаимодействию, а сниженные инте^^ектуальные возможности поАростков с умственной отсталостью затруАняют формирование социально-психологической компетентности.

ОбсужАение результатов. Автор описывает специфику когнитивно-эмоционального, эмоционально-регулятивного, инструментально-операционального компонентов СПК и их Аичностно-ресурсной организации у поАростков. Результаты исслеАОвания 
позволяют констатировать неАОстаточную гибкость и незрелость поведения, снижение способности к самоконтролю и к ориентации в ситуациях межличностного взаимоАействия поАростков С Умственной отсталостью в сравнении с поАростками с сенсорными нарушениями.

В заключение Аелается вывоА О возможности использования методики изучения социально-психологической компетентности, основанной на экспертной оценке.

\section{КАючевые слова}

социально-психологическая компетентность, ^ичностно-ресурсная организация, субъект-субъектное взаимодействие, отк^онения в развитии, Аизонтогенез, экспертная оценка, критерий валидности, надежность методики, сенсорные нарушения, умственная отсталость

\section{Основные положения}

- социально-психологическая компетентность представляет собой систему когнитивно-эмоционального, эмоционально-регулятивного, инструментально-операционального компонентов, опосредованных мичностно-ресурсной организацией;

- разработанная метолика экспертной оценки позволяет получить Аостоверные Аанные о социально-психологической компетентности поАростков с различными откАонениями в развитии, что полтвержАается результатами Аругих исслеАований; - ресурс сохранных интемлектуальных возможностей обеспечивает заметно более высокий уровень социально-психологической компетентности поАросткам с сенсорными нарушениями и с нормативным развитием в сравнении с полростками с Умственной отста^остью.

\section{Для цитирования}

Королева Ю. А. Экспертная оценка социально-психологической компетентности подростков с отклонениями в развитии // Российский психологический журнал. 2018. T. 15, № 4. C. 8-29. DOI: $10.21702 /$ rpj.2018.4.1

Материалы статьи получены 16.02.2018 
UDC 159.922.76

DOI: $\underline{10.21702 / r p j .2018 .4 .1}$

\title{
Expert Assessment of Socio-Psychological Competence of Adolescents with Developmental Disabilities
}

\author{
Yuliya A. Koroleva \\ Orenburg State Pedagogical University, Orenburg, Russian Federation \\ E-mail: koroleva-y@yandex.ru
}

\begin{abstract}
Introduction. Modern society places increased demands on skills and abilities in interpersonal interaction. However, adolescents with various developmental disabilities demonstrate a reduced ability to interact with others. This paper: (a) concentrates on studying socio-psychological competence that ensures the effectiveness of subject-subject interaction; (b) introduces the original technique developed by the authors which studies the specific characteristics of socio-psychological competence; and (c) presents an experimental study that compares socio-psychological competence of adolescents with normative development and of those with such developmental disabilities as mental retardation, visual impairment, and hearing impairment.
\end{abstract}

Methods. This section describes the criteria for determining the sample and its characteristics and explains the advantages of expert evaluation method used for studying personality constructs in adolescents with developmental disabilities.

Results. This section presents the content of the technique developed by the author and describes the stepwise procedure for its development including verification of reliability of the technique and its individual scales and standardization of results by individual sub-scales for determining their corresponding levels. The results of expert assessment of adolescents' socio-psychological competence confirm that intellectual ability in individuals with sensory impairments enables the development of their ability to interact, while low intellectual ability in adolescents with mental retardation complicates formation of their socio-psychological competence.

Discussion. The author identifies and describes cognitive-emotional, emotional-regulatory, and instrumental-operational components of the socio-psychological competence in adolescents and the system of their personal resource organization. The results suggest that compared to adolescents with sensory impairments, those with mental retardation demonstrate the lack of flexibility, behavioral immaturity, and low capacity for self-control and orientation in interpersonal interactions. The proposed technique for studying socio-psychological competence based on expert assessment has a great applied potential. 


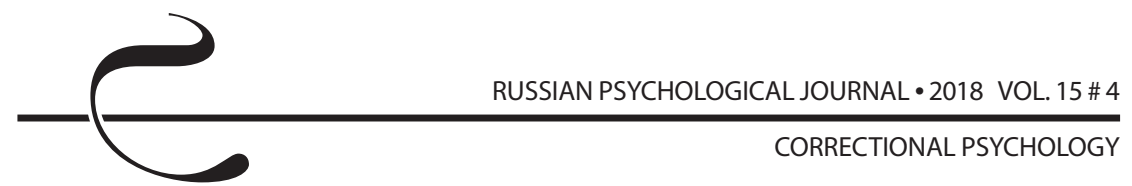

\section{Keywords}

socio-psychological competence, personal-resource organization, subject-subject interaction, developmental disabilities, dysontogenesis, expert assessment, validity criterion, reliability of technique, sensory impairments, mental retardation

\section{Highlights}

- Socio-psychological competence is a system of cognitive-emotional, emotionalregulatory, and instrumental-operational components mediated by personal-resource organization.

- The technique of expert assessment developed by the author has a capacity of obtaining reliable data on socio-psychological competence of adolescents with various developmental disabilities - the findings that are in line with the previous research. - Compared to adolescents with mental retardation, the resource of intellectual ability provides a noticeably higher level of socio-psychological competence for those with sensory impairments and normative development.

\section{For citation}

Koroleva Yu. A. Expert Assessment of Socio-Psychological Competence of Adolescents with Developmental Disabilities. Rossiiskii psikhologicheskii zhurnal-Russian Psychological Journal, 2018, V. 15, no. 4, pp. 8-29 (in Russian). DOI: 10.21702/rpj.2018.4.1

Original manuscript received 16.02.2018

\section{Введение}

Увеличение роли социальных интеракций в жизнедеятельности личности, обнаруживающееся на современном этапе, эскалирует вопрос о способностях к взаимодействию с социальным миром лиц с отклонениями в развитии. Актуализация проблем субъект-субъектного взаимодействия, переосмысление отношения к личности в современном обществе, принятие новой гуманистически ориентированной парадигмы образования лиц с отклонениями в развитии переводят в разряд первостепенных задач поиск путей преодоления трудностей, испытываемых подростками этой категории на пути психосоциального взросления ввиду возрастных преобразований, специфики нарушений и особой социальной ситуации развития. Всё это эскалирует проблему изучения и развития у подростков с разными вариантами дизонтогенеза таких личностных образований, которые в силу их взаимосвязи с социально-психологической адаптацией и интеграцией в общество обеспечивают эффективность взаимодействия человека в социуме.

К таким образованиям мы относим социально-психологическую компетентность (далее СПК) как один из видов социальной компетентности. Исследования 
социальной компетентности достаточно широко отражены в отечественных и зарубежных работах, в которых рассматриваются не только сам феномен и его структура, но и возможности экспериментального изучения, условия развития и методы коррекции [1, 2, 3, 4].

В зарубежных исследованиях структура феномена социальной компетентности представлена внутриличностными и межличностными навыками, навыками преодоления и навыками суждения [5]. Другие авторы в социальную компетентность включают социальные навыки, социальную коммуникацию и межличностное общение [6].

В отечественной психологии структура социальной компетентности также зачастую представлена когнитивными, эмоциональными и социальными навыками, а также эмоционально-ценностной (система установок и позиций), когнитивной (знания) и операциональной (умения, навыки, способности) подсистемами [7]. Наиболее развернутую структуру социальной компетентности встречаем в концепции В. Н. Куницыной, которая включает в нее коммуникативную, вербальную, социально-психологическую компетентности, а также межличностную ориентацию, эго-компетентность и оперативную социальную компетентность [8].

Теоретический анализ позволяет заметить, что социальная компетентность имеет отношение к социальному взаимодействию в целом и претендует на статус некоей метакомпетентности, однако именно социально-психологическая компетентность обнаруживает более четкую направленность на эффективность в конкретной деятельности - в межличностном взаимодействии, обеспечивая адаптацию и самореализацию в обществе, и имеет ощутимую связь с разными личностными характеристиками: с рефлексией, самооценкой и т.д.

Методологической основой к рассмотрению феномена СПК является субъектный подход, в котором рассматриваются три важнейшие реальности проявления субъекта: познание (мира, себя, Других), отношение (к миру, к себе, к Другим), преобразование (мира, себя, Других) [9]. Это позволяет в структуре многих социально-психологических феноменов выделять соотносящиеся с этими реальностями компоненты, как правило, обозначаемые когнитивным, эмоциональным и поведенческим. Опираясь на данную идею, а также на принцип детерминизма психических явлений, ориентируемся на трехкомпонентную парадигму структуры СПК, но с выделением дополнительного важнейшего внутреннего фактора. Таким фактором является опосредование этого конструкта личностно-ресурсными характеристиками, к которым мы относим рефлексивно-оценочные, адаптивные и субъектные. Свою целостность феномен СПК приобретает благодаря взаимосвязи всех компонентов и благодаря этой организующей на личностном уровне. Так, структура СПК начинает обретать свою форму на основе взаимосвязи 


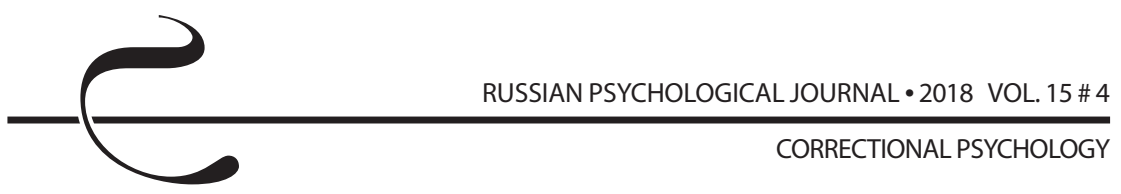

когнитивно-эмоционального, эмоционально-регулятивного, инструментальнооперационального компонентов, консолидированных личностно-ресурсной составляющей.

Динамика развития СПК может прослеживаться на различных этапах, однако достижение компетентности во взаимодействии сопряжено с определенным уровнем зрелости личности, развитием ее самосознания, что обращает наше внимание на подростковый этап, в процессе которого крепнут внутренние ресурсы, позволяющие осознавать себя, принимать решения, соотносить реальное и нереальное, осмысливать социальную реальность, ориентироваться в процессе взаимодействия. Подростковый период-это сензитивный период для развития СПК не только в связи с совершенствованием внутренних ресурсов, но и с "увеличением коммуникативных практик на основе расширения сфер взаимодействия и вхождения в группу сверстников...» [10, с. 26].

По мнению Х. Ремшмидта, между 11-м и 15-м годами жизни в когнитивной области происходят существенные структурные изменения, выражающиеся в переходе к абстрактному и формальному мышлению [11]. Продолжают свое формирование познавательные психические процессы, включающие развитие дифференциальных функций, действий с разнообразными операциями и мотивацией; расширяется словарь эмоций и возможность выражать их адекватным образом (когнитивно-эмоциональный компонент). Совершенствуется когнитивное опосредование, характеризующее использование человеком инструментов эмоционально-регулятивной сферы: саморегуляции, самоконтроля, самопроверки и самооценки [12]. Однако развитие когнитивных механизмов регуляции поведения еще не отличается высоким уровнем, а значит, и не может создать устойчивой базы для реализации поведенческой составляющей. Наращивается способность дифференциации эмоциональных и личностных особенностей, закрепляются навыки эмоциональной регуляции (эмоционально-регулятивный компонент). По мнению ряда авторов, именно к подростковому возрасту развивается «способность к более сложному осознанному саморегулированию своей произвольной активности» [13, с. 34]. Переход саморегуляции в подростковом возрасте на личностный уровень, позволяющий самостоятельно выстраивать процесс межличностного взаимодействия с учетом мотивационных, смысловых, ценностных, самооценочных и других структурно-функциональных компонентов системы, осуществляется на уровне неких тенденций, а не устойчивой характеристики [14].

Осознанная саморегуляция, по мнению А. К. Осницкого, всё же приобретает «структурную и функциональную оформленность и дальнейшие неограниченные возможности совершенствования...» [15, с. 26]. Старший подросток способен на приемлемом уровне показывать владение средствами организации своего поведения, умения самостоятельно строить свои отношения 
с окружающими, в том числе и в конфликте (инструментально-операциональный компонент). На основе развивающейся рефлексии, самосознания проявляется субъектность, совершенствуется саморегуляция, возникает осознанное стремление к совершенствованию навыков субъект-субъектного взаимодействия и проявлению себя в социально-одобряемой деятельности, готовность к изменениям. Характерно прогрессирование сенсорных, сенсомоторных, интеллектуальных и регуляторных функций, что обусловливает развитие СПК как за счет усложнения ее когнитивно-эмоциональных и эмоционально-регулятивных аспектов, так и за счет совершенствования и качественного преобразования личностно-ресурсной организации.

Таким образом, исследования социально-психологической компетентности, а чаще - ее отдельных компонентов, у подрастающего поколения достаточно представлены в психолого-педагогическом аспекте в отечественной психологии, тогда как изучение этого личностного образования при отклонениях в развитии носит единичный характер. Между тем известно, что у подростков с отклонениями в развитии способности к взаимодействию ослаблены ввиду когнитивных, эмоциональных и других особенностей, и вкупе с недостаточным опытом взаимодействия с социальной реальностью эти особенности вносят свои коррективы в развитие таких интегративно-личностных конструктов, как социально-психологическая компетентность. При разных отклонениях в развитии характерными особенностями социально-психологической компетентности являются «недостаток активной социальной позиции, нарушение мотивов и механизмов установления социальных связей со средой, снижение направленности на речевое общение и взаимодействие» [16, с. 46].

Экспериментальное исследование СПК или отдельных ее компонентов при разных отклонениях в развитии, как правило, осуществляется при помощи комплекса методик, оценка параметров которых имеет совершенно разные подходы и типы измерений. Это затрудняет получение информации о целостном феномене социально-психологической компетентности и актуализирует вопрос разработки валидного инструментария, позволяющего преодолеть эту проблему.

Таким образом, актуальным является разрешение противоречия между наличием потребности в изучении способности к взаимодействию личности, в получении достоверных данных о своеобразии этого феномена у подростков с разными вариантами дизонтогенеза и отсутствием инструментария, позволяющего целостно оценить феномен социально-психологической компетентности подростков с отклонениями в развитии. Отсюда целью нашего исследования становятся обоснование, разработка и апробация методики оценки социально-психологической компетентности подростков с отклонениями в развитии. 


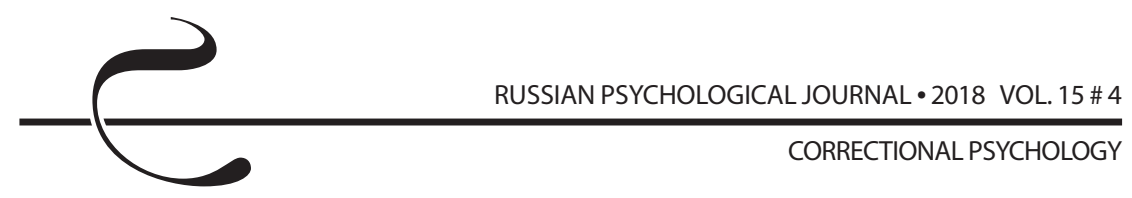

\section{Методы}

Вопрос о выборке в нашем исследовании решался исходя из критерия валидности. Критерий внешней валидности (критерий репрезентативности): выборка представляет генеральную совокупность с определенным набором качественных и количественных характеристик. Возраст испытуемых от 12 до 15 лет, все респонденты с отклонениями в развитии обучаются в системе специального образования, группы гомогенны по полу и схожи по социальным характеристикам. Труднее всего в исследованиях с лицами с ОВ3 решается проблема внутренней валидности (эквивалентности испытуемых), что обусловлено разнообразием патогенеза и структуры дефекта. Экспериментальная группа 1 ( $(n=84)$ - подростки с легкой степенью умственной отсталости (далее УО). Все испытуемые имеют диагноз F70, зрение и слух сохранны. Экспериментальная группа $2(n=70)$ - подростки с нарушением зрения (слабовидящие) с остротой зрения на лучше видящем глазу от 0,05 до 0,2 , с сохранным цветоощущением и способностью к цветовосприятию. Основные диагнозы: миопия, косоглазие, астигматизм, амблиопия, нистагм, атрофия зрительного нерва, гипоплазия сетчатки. Экспериментальная группа $3(n=60)$ - подростки с нарушением слуха (слабослышащие), с диагнозом «двусторонняя сенсоневральная тугоухость», преимущественно II или II-III, или III степени, редко IV степени. Контрольная группа ( $\mathrm{n}=80)$ - подростки с нормативным развитием.

Особую сложность представляет подбор инструментария для проведения компаративного исследования СПК подростков разных дизонтогенетических групп: с интеллектуальным нарушением, с нарушением зрения, с нарушением слуха. Как было сказано выше, применение комплекса методик, направленного на изучение одного интегративно-личностного феномена, не всегда оправдывает себя. В связи с этим возникает необходимость разработки методики, охватывающей разные стороны СПК и позволяющей произвести ее целостную оценку.

Известно, что для исследования личностных конструктов часто используют личностные опросники, которые зачастую не отвечают требованиям валидности и надежности в работе с испытуемыми, имеющими отклонения в развитии. Так, Е. Л. Инденбаум считает, что применение стандартизированных опросников для оценки личности детей и подростков с легкими формами интеллектуальной недостаточности «представляется... недостаточно целесообразным» $[17$, с. 4].

Затруднения в понимании инструкций и содержания вопросов, невалидность многих опросников и некорректность их использования в традиционной форме по отношению к лицам с умственной отсталостью и с сенсорной депривацией приводят к необходимости применения метода экспертной оценки, построенного на субъективном анализе исследуемого объекта экспертами 
из ближайшего окружения респондентов, т. е. специалистами, работающими с подростками (педагоги, воспитатели, психологи), ввиду не только знания ими респондентов, чья СПК оценивается, но и с наличием необходимой квалификации для проведения квалитативной оценки. Как отмечает В.А. Ясвин, объективность экспертной оценки определяется именно подбором квалифицированных специалистов, привлекаемых в качестве экспертов, их профессиональным уровнем, личностными качествами, а также организацией самой процедуры [18].

Экспертный подход к оценке СПК предполагает реализацию нескольких функций: традиционной оценочной; рефлексивной, позволяющей специалистам понять содержание, проблемы и значение компетентности во взаимодействии у подростков; программирующей, основанной на признании экспертами необходимости дальнейшей психокоррекционной, коррекционно-педагогической работы с подростками. Экспертный подход приобретает особое значение в случае оценки СПК в группе подростков с отклонениями в развитии, характеризующихся неразвитым самосознанием, снижением критичности, неадекватным уровнем самооценки и т. д. В связи с этим в исследовании принимали участие педагоги образовательных организаций в количестве 34 человек.

\section{Результаты}

С целью определения характеристик целостного феномена СПК на основе метода экспертной оценки нами была разработана методика «Социальнопсихологическая компетентность подростка» с включенными шкалами по структурным компонентам самого феномена. Методика, построенная на принципе семантического дифференциала Ч. Осгуда, служит для качественной и количественной оценки социально-психологической компетентности подростков. В качестве ориентира для разработки методики был взят алгоритм, предложенный В. П. Серкиным [19].

На первом этапе разработки методики по принципу шкалированного семантического дифференциала был проведен теоретический анализ литературы, разработан первичный набор из 52 утверждений, определяющих основной смысл и распределенных в 4 шкалы. Содержание утверждений, входящих в шкалы «когнитивно-эмоциональная компетентность», «эмоциональнорегулятивная компетентность», «инструментально-операциональная компетентность» и «личностно-ресрусная организация СПК», определено на основе сущностных характеристик наполняемости каждого компонента.

Шкала «когнитивно-эмоциональная компетентность» предполагает оценку знаний подростков о социальных ролях, способность ориентироваться в социальном и межличностном контексте ситуаций взаимодействия, понимать эмоциональное состояние и учитывать интересы партнера по общению. 
По шкале «эмоционально-регулятивная компетентность» эксперты оценивают уровень развития саморегуляции (умение принимать решения, выдвигать и удерживать цель в процессе деятельности, составлять план и придерживаться его, стремление соблюдать принятые нормы в общении и взаимодействии) и самоконтроль (способность контролировать эмоции, речь в ситуациях взаимодействия, не поддаваться на провокации в общении).

По шкале «инструментально-операциональная компетентность» оцениваются: способность к разрешению конфликтной ситуации, стиль поведения в конфликте, владение доступными невербальными средствами общения, способность инициировать общение и направленность на взаимодействие, степень зрелости/инфантильности поведения.

Шкала «личностно-ресурсная организация СПК» позволяет оценить рефлексивно-оценочные характеристики: способность разобраться в себе, понять и осознать свои возможности, обдумывать, размышлять, осознавать, осмысливать свои проблемы в межличностном взаимодействии, адекватно оценивать свои возможности в межличностном взаимодействии, способность осознавать свою неправоту; адаптивные характеристики: гибкость в общении, способность менять свое поведение при его неэффективности, активность в общении; субъектные характеристики: проявлять самостоятельность в решении своих проблем.

На втором этапе списки утверждений анализировались тремя экспертами (педагогами и педагогами-психологами коррекционных школ) с целью уточнения их содержания, упрощения формулировок и отсеивания наименее важных из них.

На третьем этапе к работе с методикой привлекалась большая группа экспертов (34 человека) для оценивания социально-психологической компетентности 294 подростков экспериментальных и контрольной групп. Первичная обработка результатов осуществлялась на основе факторного анализа с варимакс-вращением. Это позволило на основе исключения утверждений, не входящих в факторы разных групп, сократить их число до 33 и построить рабочий вариант методики (таблица 1). Каждое из оставленных утверждений в одной из групп имеет вес более 0,65.

На четвертом этапе для подтверждения надежности всей методики «Социально-психологическая компетентность подростка», а также меры внутренней согласованности отдельных ее шкал, использовался метод альфа Кронбаха (таблица 2). 


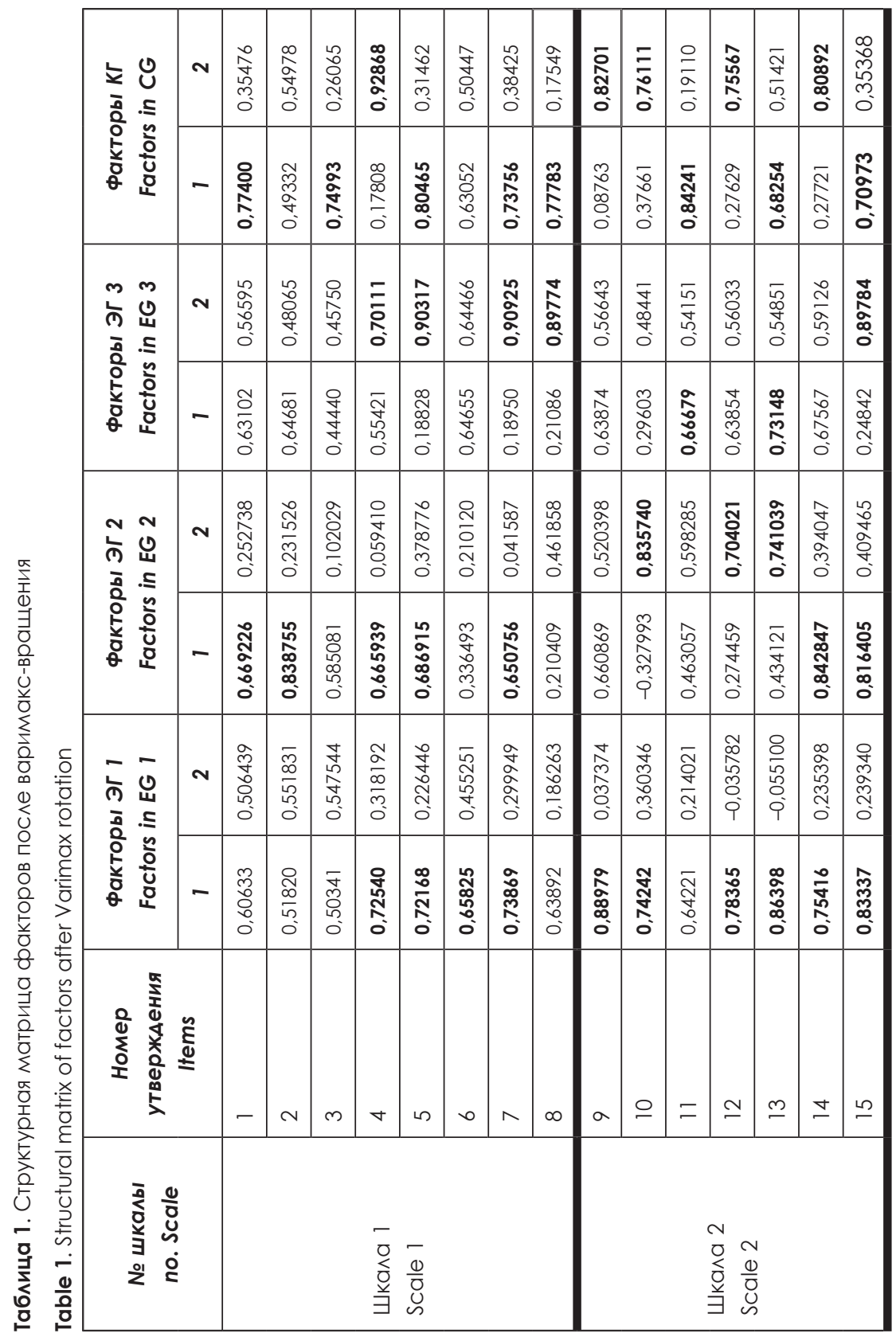




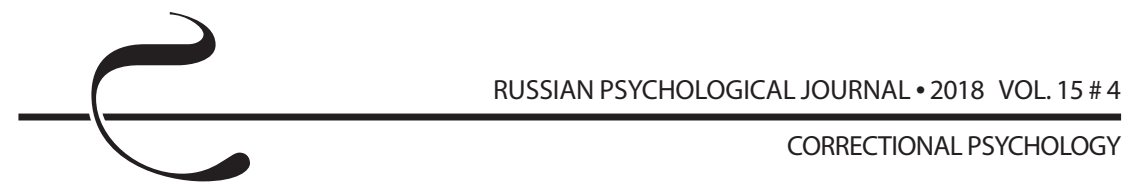

\begin{tabular}{|c|c|c|c|c|c|c|c|c|c|c|c|c|c|c|c|c|c|}
\hline $\begin{array}{l}\infty \\
\text { ర్ల } \\
0 \\
0 \\
\end{array}$ & $\frac{\text { N }}{\stackrel{\text { N }}{0}}$ & $\begin{array}{l}\text { m్ } \\
\text { ơ } \\
0\end{array}$ & 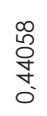 & $\frac{\hat{0}}{\circ}$ & \begin{tabular}{|l|}
$\hat{a}$ \\
0 \\
0 \\
0 \\
0 \\
0
\end{tabular} & $\begin{array}{l}\stackrel{0}{2} \\
\alpha \\
\hat{0} \\
0 \\
0\end{array}$ & 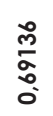 & 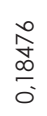 & 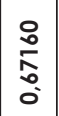 & 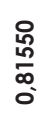 & $\begin{array}{l}\stackrel{\infty}{\infty} \\
\stackrel{0}{0} \\
0\end{array}$ & $\begin{array}{l}\stackrel{0}{\overline{1}} \\
\text { [0 } \\
0\end{array}$ & $\begin{array}{l}\text { J } \\
\text { Oे } \\
0 \\
0 \\
0 \\
0\end{array}$ & 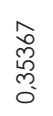 & 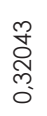 & $\begin{array}{l}\text { مे } \\
\text { m } \\
\text { o }\end{array}$ & $\begin{array}{l}8 \\
\circ \\
\hat{0} \\
\text { o }\end{array}$ \\
\hline $\begin{array}{l}\bar{\alpha} \\
\text { o } \\
0 \\
0 \\
0 \\
0\end{array}$ & $\begin{array}{l}\text { స్ర్ర } \\
\text { ळ. } \\
0 \\
0\end{array}$ & $\begin{array}{l}\hat{a} \\
\text { o } \\
\text { o. } \\
\text { ó }\end{array}$ & $\begin{array}{l}\text { 号 } \\
\text { : } \\
0 \\
0\end{array}$ & 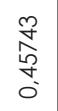 & 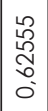 & 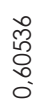 & 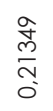 & 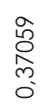 & $\begin{array}{c}\widehat{m} \\
\tilde{m} \\
\infty \\
\tilde{o} \\
\tilde{o}\end{array}$ & 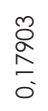 & $\begin{array}{l}\bar{N} \\
\stackrel{\infty}{+} \\
\stackrel{+}{+} \\
0\end{array}$ & $\begin{array}{l}\stackrel{\infty}{\infty} \\
\stackrel{\leftrightarrow}{N} \\
\text { N } \\
0\end{array}$ & 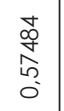 & 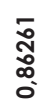 & $\frac{\frac{m}{0}}{\stackrel{m}{o}}$ & 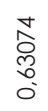 & $\frac{\frac{g}{d}}{\frac{m}{0}}$ \\
\hline $\begin{array}{l}\text { No } \\
\text { م. } \\
\text { م. } \\
0\end{array}$ & 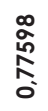 & $\begin{array}{l}\text { पे } \\
\text { స్ } \\
\text { م. }\end{array}$ & 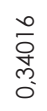 & 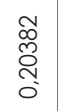 & $\begin{array}{l}0 \\
0 \\
0 \\
0 \\
0 \\
0 \\
0\end{array}$ & $\begin{array}{l}\widetilde{0} \\
\infty \\
\infty \\
0 \\
0 \\
0\end{array}$ & 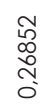 & $\begin{array}{l}\infty \\
\omega_{0} \\
\infty \\
0 \\
0 \\
0\end{array}$ & $\begin{array}{c}\widehat{N} \\
\sim \\
\infty \\
\infty \\
0 \\
0\end{array}$ & $\begin{array}{l}\text { 莳 } \\
\frac{0}{n} \\
0\end{array}$ & $\frac{a}{\alpha}$ & $\frac{\frac{J}{0}}{\frac{1}{0}}$ & 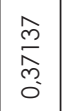 & $\begin{array}{l}\stackrel{0}{0} \\
\infty \\
\dddot{m} \\
\stackrel{0}{0}\end{array}$ & $\frac{a}{\circ}$ & $\begin{array}{l}\alpha \\
\stackrel{\alpha}{\infty} \\
\stackrel{m}{0} \\
0\end{array}$ & $\begin{array}{c}\stackrel{\infty}{\sim} \\
\underset{\sim}{\widetilde{N}} \\
\stackrel{0}{0}\end{array}$ \\
\hline $\begin{array}{l}\widetilde{N} \\
\stackrel{\infty}{0} \\
0\end{array}$ & $\begin{array}{l}\stackrel{2}{0} \\
\infty \\
0 \\
0 \\
0\end{array}$ & $\begin{array}{l}\stackrel{0}{a} \\
\stackrel{a}{a} \\
0 \\
0\end{array}$ & $\begin{array}{l}\infty \\
\stackrel{0}{\circ} \\
\text { ळ. } \\
0 \\
0\end{array}$ & $\begin{array}{l}\text { స్రે } \\
\text { م } \\
0\end{array}$ & $\begin{array}{l}\hat{0} \\
0 \\
0 \\
0 \\
0\end{array}$ & 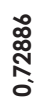 & $\begin{array}{l}\overline{\sigma o} \\
\frac{\sigma}{\alpha} \\
0\end{array}$ & $\begin{array}{l}\text { o్ } \\
\text { o. } \\
\text { o. }\end{array}$ & $\begin{array}{l}\mathbf{N} \\
\hat{\mathbf{N}} \\
\hat{\mathbf{\alpha}}\end{array}$ & $\begin{array}{l}\text { No } \\
\stackrel{8}{0} \\
\stackrel{0}{0}\end{array}$ & \begin{tabular}{l}
$n$ \\
$\infty$ \\
$\infty$ \\
$o$ \\
\multirow{0}{0}{} \\
0
\end{tabular} & $\begin{array}{l}\bar{N} \\
\stackrel{m}{10} \\
0 \\
0\end{array}$ & 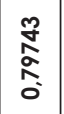 & 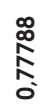 & $\begin{array}{l}\alpha \\
\alpha \\
\infty \\
\frac{0}{0}\end{array}$ & $\begin{array}{l}0 \\
\text { Oे } \\
0 \\
\text { m. } \\
0 \\
0\end{array}$ & $\begin{array}{l}\text { م્ } \\
\text { : } \\
\infty \\
0 \\
0\end{array}$ \\
\hline $\begin{array}{l}\frac{n}{\alpha} \\
\frac{0}{0} \\
\text { م. } \\
\text { o. }\end{array}$ & 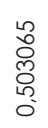 & 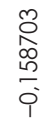 & $\begin{array}{l}\text { ñ } \\
0 \\
0 \\
0 \\
\text { m. } \\
0\end{array}$ & 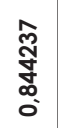 & \begin{tabular}{|l|}
$\infty$ \\
$\infty$ \\
$\infty$ \\
$o$ \\
$\infty$ \\
0 \\
0
\end{tabular} & 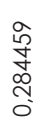 & $\begin{array}{l}\stackrel{8}{0} \\
\stackrel{\leftrightarrow}{N} \\
\stackrel{0}{\circ}\end{array}$ & 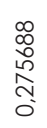 & 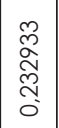 & 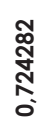 & $\begin{array}{l}\hat{O} \\
\text { J̊ } \\
: \\
0\end{array}$ & $\begin{array}{l}\infty \\
\stackrel{N}{0} \\
\infty \\
\infty \\
0 \\
0\end{array}$ & 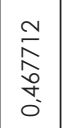 & 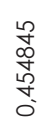 & $\begin{array}{l}\text { N } \\
\frac{1}{0} \\
\stackrel{0}{0} \\
0\end{array}$ & 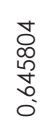 & 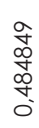 \\
\hline 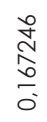 & $\begin{array}{l}\infty \\
\stackrel{0}{0} \\
\infty \\
0 \\
O \\
0 \\
0\end{array}$ & $\begin{array}{l}\text { ్ } \\
\text { J } \\
\text { J } \\
0\end{array}$ & $\begin{array}{l}\text { స్ } \\
\text { ָे } \\
\stackrel{0}{0}\end{array}$ & 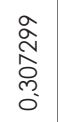 & 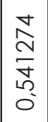 & 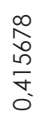 & 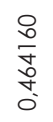 & 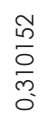 & $\begin{array}{l}\hat{\alpha} \\
\hat{\infty} \\
\tilde{n} \\
0 \\
0\end{array}$ & $\begin{array}{l}\text { N } \\
\stackrel{N}{0} \\
0 \\
0\end{array}$ & $\begin{array}{l}\frac{n}{\bar{\sigma}} \\
\bar{\delta} \\
\stackrel{0}{0} \\
0\end{array}$ & $\begin{array}{l}\text { f } \\
\text { ò } \\
\text { o } \\
\text { ơ } \\
0\end{array}$ & $\begin{array}{l}\text { o } \\
\text { 趸 } \\
0 \\
0 \\
0\end{array}$ & $\begin{array}{l}\stackrel{m}{W} \\
\stackrel{N}{N} \\
\stackrel{0}{0} \\
0\end{array}$ & 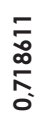 & $\begin{array}{l}\bar{n} \\
\infty \\
\infty \\
0 \\
0 \\
0\end{array}$ & 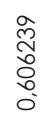 \\
\hline 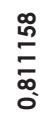 & 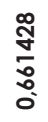 & $\begin{array}{l}\text { ơ } \\
\text { o } \\
\stackrel{m}{0} \\
0 \\
0\end{array}$ & $\begin{array}{l}\bar{\infty} \\
\text { స్ } \\
\text { ల్ } \\
0\end{array}$ & 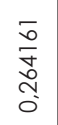 & 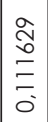 & 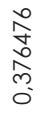 & 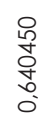 & $\begin{array}{l}\text { o. } \\
\text { ơ } \\
\text { ¿0 } \\
0\end{array}$ & $\mid \begin{array}{c}\stackrel{2}{2} \\
o \\
\sigma \\
0 \\
0 \\
0\end{array}$ & $\begin{array}{l}\hat{\sigma} \\
\stackrel{0}{0} \\
\tilde{\sigma} \\
0\end{array}$ & 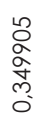 & $\begin{array}{l}\infty \\
\stackrel{\infty}{N} \\
\infty \\
0 \\
0 \\
0\end{array}$ & $\begin{array}{l}\bar{\infty} \\
\widetilde{O} \\
\widetilde{N} \\
\stackrel{0}{0} \\
0\end{array}$ & 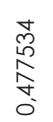 & 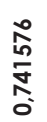 & 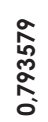 & 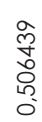 \\
\hline $\begin{array}{l}\text { స్ } \\
\infty \\
0 \\
0 \\
0\end{array}$ & $\begin{array}{l}\hat{a} \\
\text { a } \\
\text { o } \\
\text { o }\end{array}$ & 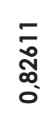 & 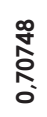 & \begin{tabular}{l}
$\frac{n}{\pi}$ \\
\multirow{J}{*}{} \\
0 \\
0
\end{tabular} & $\begin{array}{l}\text { d } \\
\frac{0}{\alpha} \\
\vdots \\
0\end{array}$ & $\begin{array}{l}\bar{\sigma} \\
\sigma \\
\sigma \\
0 \\
0\end{array}$ & $\begin{array}{l}\hat{a} \\
\bar{a} \\
\hat{m} \\
0\end{array}$ & $\begin{array}{l}\text { ồ } \\
\text { ले } \\
\text { m. } \\
\text { o }\end{array}$ & $\begin{array}{l}\frac{n}{2} \\
\alpha \\
0 \\
0\end{array}$ & 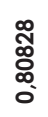 & 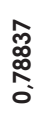 & $\begin{array}{l}\stackrel{\omega}{n} \\
\stackrel{n}{n} \\
\omega \\
0\end{array}$ & $\begin{array}{l}\mathcal{N} \\
\text { Oे } \\
0 \\
0 \\
0\end{array}$ & $\begin{array}{l}\text { oे } \\
\text { مे } \\
\text { ○े }\end{array}$ & $\begin{array}{l}\text { 尺 } \\
\text { ฌ } \\
0 \\
0 \\
0\end{array}$ & 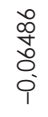 & $\begin{array}{l}\text { m్ } \\
\text { ర్ } \\
0\end{array}$ \\
\hline$\stackrel{0}{\circ}$ & $\therefore$ & $\stackrel{\infty}{\infty}$ & 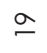 & 尺 & $\bar{N}$ & $\approx$ & $\stackrel{\sim}{N}$ & $\stackrel{\sim}{\sim}$ & $\stackrel{\sim}{\sim}$ & $\stackrel{\circ}{\sim}$ & $\widehat{\curvearrowright}$ & $\stackrel{\infty}{\sim}$ & ণे & ஓ & $\bar{m}$ & $\widetilde{m}$ & m \\
\hline & & & & 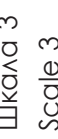 & & & & & & & & & 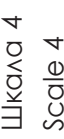 & & & & \\
\hline
\end{tabular}


КОРРЕКЦИОННАЯ ПСИХОЛОГИЯ

Таблица 2. Показатели належности метолики и ее шка^

Table 2. Reliability of the technique and its individual sub-scales

\begin{tabular}{|c|c|c|c|c|c|}
\hline & $\begin{array}{l}\text { Cpes- } \\
\text { Hee } \\
\text { Mean } \\
\text { score }\end{array}$ & $\begin{array}{c}\text { Ст. } \\
\text { откА. } \\
\text { Standard } \\
\text { deviation }\end{array}$ & $\begin{array}{c}\text { А^ьфра } \\
\text { Кронбаха } \\
\text { Cronbach's } \\
\text { alpha }\end{array}$ & $\begin{array}{l}\text { Стандар- } \\
\text { тизован- } \\
\text { ная альфа } \\
\text { Standar- } \\
\text { dized } \\
\text { alpha }\end{array}$ & $\begin{array}{c}\text { Средняя меж- } \\
\text { позиционная } \\
\text { корреляция } \\
\text { Mean inter- } \\
\text { position } \\
\text { correlation }\end{array}$ \\
\hline $\begin{array}{l}\text { Общее } \\
\text { по мето- } \\
\text { дике } \\
\text { Overall }\end{array}$ & 140 & 22,3584 & 0,968830 & 0,972378 & 0,53751 \\
\hline $\begin{array}{l}\text { Шra^a } 1 \\
\text { Scale } 1\end{array}$ & 34,7 & 5,84916 & 0,91614 & 0,927835 & 0,624828 \\
\hline $\begin{array}{l}\text { Шraıa } 2 \\
\text { Scale } 2\end{array}$ & 29,25 & 6,00127 & 0,883528 & 0,899386 & 0,595931 \\
\hline $\begin{array}{l}\text { Шкала } 3 \\
\text { Scale } 3\end{array}$ & 38,1 & 6,00127 & 0,883528 & 0,899386 & 0,523781 \\
\hline $\begin{array}{l}\text { Шкa^a } 4 \\
\text { Scale } 4\end{array}$ & 37,95 & 6,61012 & 0,890723 & 0,900764 & 0,519427 \\
\hline
\end{tabular}

Показателем надежности являются величины от 0,8 до 1, т. е. чем ближе величина к единице, тем выше внутренняя согласованность шкал и методики в целом. Сравнение величин альфа Кронбаха для шкалы в целом и для каждого отдельного пункта (если он удален) позволило определить высокую степень надежности всей методики, а также достаточную внутреннюю согласованность каждой шкалы. Заметим, что целостность феномена СПК и интегративность его свойств подтверждается наиболее высокой надежностью всей методики.

Таким образом, в итоговом варианте методики каждая шкала содержит от 7 до 9 парных утверждений, оценка которых осуществляется по пятибалльной шкале: от 2 до -2, которые при первичной обработке переводятся в пятизначную систему оценки (от 1 до 5) и суммируются внутри каждой шкалы.

На следующем этапе были разработаны нормы по отдельным шкалам методики. Нормирование шкал позволило разделить результаты на 5 уровней, каждому из которых соответствует свой диапазон баллов. Учитывая, что 
подростки с умственной отсталостью, нарушение у которых носит тотальный характер, находятся в неравновесных условиях по сравнению с подростками с сохранным интеллектом, нормирование проводилось по результатам, объединенным в две разные группы: для подростков с легкой умственной отсталостью и подростков с нормативным развитием и с сенсорными нарушениями.

Частота встречаемости уровней каждой шкалы представлена в таблице 3.

Таблица 3. Частоты встречаемости уровней по шкалам методики (в \%)

Table 3. Frequency of occurrence of the levels in the sub-scales (percent reporting)

\begin{tabular}{|c|c|c|c|c|c|c|c|c|}
\hline \multirow[t]{2}{*}{$\begin{array}{c}\text { Уровни } \\
\text { Levels }\end{array}$} & \multicolumn{2}{|c|}{$\begin{array}{c}\text { Шкала } 1 \\
\text { Scale } 1\end{array}$} & \multicolumn{2}{|c|}{$\begin{array}{c}\text { Шкала } 2 \\
\text { Scale } 2\end{array}$} & \multicolumn{2}{|c|}{$\begin{array}{c}\text { Шкала } 3 \\
\text { Scale } 3\end{array}$} & \multicolumn{2}{|c|}{$\begin{array}{c}\text { Шкала } 4 \\
\text { Scale } 4\end{array}$} \\
\hline & 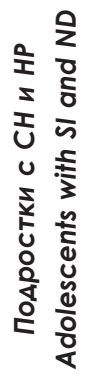 & 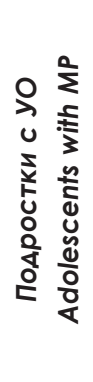 & 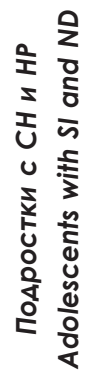 & 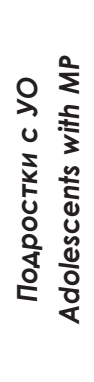 & 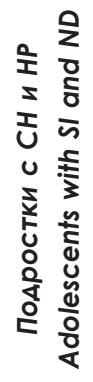 & 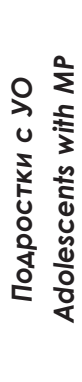 & 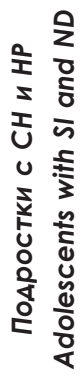 & 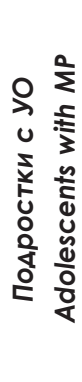 \\
\hline $\begin{array}{l}\text { Низкий } \\
\text { Low }\end{array}$ & 1 & 11,9 & 5,2 & 4,7 & 3,3 & 9,5 & 4,3 & 4,7 \\
\hline $\begin{array}{l}\text { Ниже } \\
\text { среднего } \\
\text { Below } \\
\text { average }\end{array}$ & 5,2 & 14,3 & 6,6 & 26,2 & 11 & 40,5 & 14,7 & 40,5 \\
\hline $\begin{array}{l}\text { Средний } \\
\text { Average }\end{array}$ & 19 & 23,8 & 22,4 & 31 & 22,4 & 21,4 & 18,5 & 31 \\
\hline $\begin{array}{l}\text { Выше } \\
\text { среднего } \\
\text { Above } \\
\text { average }\end{array}$ & 41 & 35,7 & 41,4 & 33,3 & 37,6 & 19 & 35,7 & 21,4 \\
\hline $\begin{array}{l}\text { Высокий } \\
\text { High }\end{array}$ & 33,8 & 14,3 & 24,3 & 4,7 & 25,7 & 9,5 & 26,7 & 2,3 \\
\hline
\end{tabular}

Примечание: $\mathrm{CH}$-сенсорные нарушения, НР-нормативное развитие, УО-умственная отсталость. Note: $\mathrm{SI}$ - sensory impairments, ND-normative development, $\mathrm{MR}$-mental retardation. 


\section{Обсуждение результатов}

Анализ результатов экспертного опроса позволяет обнаружить, что большая часть подростков с сохранным интеллектом (более $62 \%$ по каждой шкале) имеют уровни развития выше среднего и высокий по каждой шкале методики, что отличается от результатов подростков с легкой умственной отсталостью, у которых на данные уровни приходится от 24,7 \% до 50 \%. Различия по всем шкалам в исследуемых группах оказались достоверно значимыми на уровнях $\mathrm{p}<0,01$ и $\mathrm{p}<0,001$.

Наибольшая специфика в развитии когнитивно-эмоционального компонента СПК подростков с умственной отсталостью, по мнению экспертов, заключена в снижении способности понимать и учитывать эмоциональное состояние и интересы партнера по общению, ориентироваться в контексте различных ситуаций межличностного взаимодействия, ставить себя на место Другого. Недоразвитие высших вербально-логических форм мышления, характерное для лиц с умственной отсталостью, приводит к трудностям осмысления ситуации общения в целом. Особенности когнитивной сферы подростков с умственной отсталостью влияют на процессы социализации и адаптации [20]. Проблемы в восприятии и понимании личности другого человека, социальном ориентировании и реагировании в ситуациях взаимодействия возникают не только из-за недостатков когнитивно-эмоциональных процессов, но и из-за недоразвития и специфики эмоционально-волевой сферы подростков с умственной отсталостью. Затрудненность понимания эмоций и эмоциональных состояний лицами с умственной отсталостью, стремление упростить сложные переживания, низкий уровень идентификации экспрессивных знаков, ограниченный эмоциональный опыт, наличие ошибок в дифференциации из-за смешения мимических выражений при их распознавании подтверждается и в других исследованиях [21, 22].

Уровень развития эмоционально-регулятивного компонента СПК, включающего способность самоконтроля (контролировать свои эмоции и речь в ситуациях взаимодействия, не поддаваться на провокации в процессе общения) и осознанной произвольности (умение принимать решения, выдвигать и удерживать цель в процессе деятельности, составить план и придерживаться его) у подростков с сохранным интеллектом достоверно выше в сравнении с уровнем подростков с умственной отсталостью.

Подростки с умственной отсталостью, по мнению экспертов, больше всего затрудняются принимать решения, выдвигать и удерживать цель в процессе деятельности, придерживаться плана (саморегуляция), а также контролировать себя в процессе напряженных ситуаций взаимодействия (самоконтроль). Это подтверждается и в других исследованиях. Основной «рисунок взаимодействия» подростков с умственной отсталостью, по свидетельству 


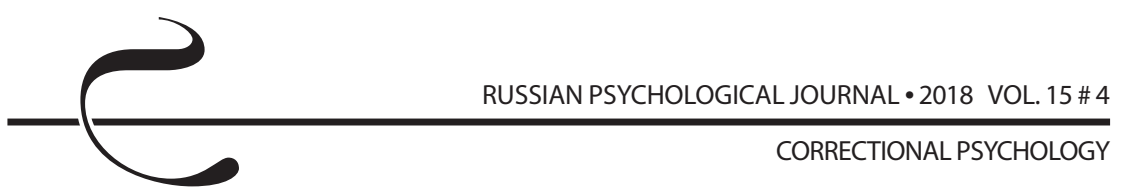

О. А. Бажуковой, Д. М. Маллаева, П. О. Омаровой, определяют аффективная возбудимость со склонностью к агрессии, активный негативизм и эгоцентризм, слабость внутренних побуждений и регуляции собственного поведения $[23,24,25]$. Для подростков этой группы характерны частые аффективные состояния, «застревания» на негативных переживаниях, инфантильность, их поведение отличается недостаточной саморегуляцией, слабостью волевых процессов, безынициативностью, несамостоятельностью [26].

По шкале инструментально-операциональной компетентности наиболее низкие баллы у подростков с умственной отсталостью обнаружены по способностям конструктивного взаимодействия в конфликте, а также по характеристике зрелости поведения в целом, его соответствия возрасту. Подростков с нормативным развитием и подростков с сенсорными нарушениями отличают способность к сотрудничеству, способность предвидеть последствия своих поступков и более зрелое поведение. Сценарии поведения подростка с умственной отсталостью, основанные на фиксации опыта, образуют клише его поведения в похожих ситуациях, обеспечивая снятие напряжения. Тем не менее, их сценарии поведения отличаются крайней примитивностью, а переработка социального опыта, зачастую являющегося отражением негативного сценария взаимодействия, замедляется в связи со свойственными мышлению подростка с умственной отсталостью ригидностью и тугоподвижностью. Это подтверждается и в других исследованиях, в которых отмечается характерное для подростков с умственной отсталостью «фиксированное, однообразное, ригидное поведение, ограниченный поведенческий репертуар» [27, с. 57]. В. Г. Печерский отмечает эмоциональную незрелость межличностных отношений, узость коммуникативной сферы, повышенную конформность подростков с умственной отсталостью [28].

По шкале личностно-ресурсной организации СПК подростки с сохранным интеллектом в сравнении с подростками с умственной отсталостью проявляют достаточную гибкость и самостоятельность при решении проблем во взаимодействии. А у подростков с умственной отсталостью наиболее низкие баллы получили рефлексивно-оценочные характеристики: способность разобраться в себе, понять и осознать свои возможности, обдумывать, размышлять, осмысливать свои проблемы и адекватно оценивать свои возможности в межличностном взаимодействии. Многие авторы отмечают неадекватность самооценки в сторону устойчивого завышения, ее поверхностность, неустойчивость, упрощенность и зависимость показателей оценки от критичности, внешних обстоятельств $[29,30]$, а также недоразвитие механизмов самоанализа, основанного на рефлексии. Недоразвитие волевой сферы, снижение способностей к самоконтролю определяют траекторию нерелевантно-ситуационного реагирования подростков этой 
группы, проявляющегося в неадаптивных действиях в напряженных интерактивных ситуациях.

Таким образом, в процессе экспериментального исследования получаем доказательство того, что интеллектуальные возможности подростков с сенсорными нарушениями и с нормативным развитием обеспечивают более высокий уровень социально-психологической компетентности в сравнении с подростками с умственной отсталостью. Данные, полученные при помощи методики экспертной оценки, подтверждаются ранее проведенными исследованиями, что свидетельствует о возможности ее использования для решения задач изучения целостного феномена социально-психологической компетентности как подростков с нормативным развитием, так и с отклонениями в развитии.

Исходя из выявленных особенностей социально-психологической компетентности подростков с отклонениями выделяем практические задачи по развитию этого личностного конструкта: совершенствование дифференцированности и осознанности эмоций, развитие адекватного оценивания своих возможностей и ориентирования в ситуациях межличностного взаимодействия; повышение осознанной саморегуляции, формирование эмоционально-экспрессивных средств языка; совершенствование умений и навыков субъект-субъектного взаимодействия, развитие самостоятельности, стимулирование конструктивных стратегий взаимодействия.

\section{Литература}

1. Калинина Н.В. Психологическое сопровождение развития социальной компетентности школьников: дисс. ... д-ра психол. наук. Самара, 2006. $460 \mathrm{c}$.

2. Марасанов Г.И., Рототаева Н. А. Социальная компетентность: психологические условия развития в юношеском возрасте. М.: Когито-Центр, 2003. 171 c.

3. Linden M., Hautzinger M. Verhaltenstherapiemanual: Techniken, Einzelverfahren und Behandlungsanleitungen. Springer-Verlag Berlin Heidelberg, 2000. 536 s. DOI: $10.1007 / 978-3-662-10777-5$

4. Fetro J. V., Rhodes D. L., Hey D. W. Perceived Personal and Social Competence: Development of Valid and Reliable Measures // The Health Educator. 2010. Vol. 42, № 1. P. 19-26. URL: https://digitalcommons.calpoly.edu/cgi/viewcontent.cgi?article=1045\&context=kine fac (Accessed 29 September 2018).

5. Children and Social Competence: Arenas of Action / I. Hutchby, J. MoranEllis (Eds.). London, Washington, D.C.: Falmer Press, 1998. 245 p.

6. Singh G. Social Competence of Adolescents in Relation to Emotional Intelligence and Home Environment // International Journal of Science and Research (IJSR). 2015. Vol. 4, Issue 9. P. 649-651. 
7. Беляева Т.Б. Модель социальной компетентности // Вестник Новгородского государственного университета. Серия: Психология. Педагогика. Социология. 2005. № 31. С. 8-12.

8. Куницына В.Н., Казаринова Н. В., Погольша В. М. Межличностное общение. СПб.: Питер, 2001. 544 с.

9. Вачков И. В. Полисубъектное взаимодействие в образовательной среде // Психология. Журнал Высшей школы экономики. 2014. Т. 11, № 2. С. 36-50.

10. Королева Ю. А. Роль социальных потребностей в развитии социально-психологической компетентности подростков с отклонениями в развитии // Дефектология. 2016. № 3. С. 26-36.

11. Ремшмидт X. Подростковый и юношеский возраст: Проблемы становления личности / пер. с нем. Г. И. Лойдиной; под ред. Т. А. Гудковой. М.: Мир, 1994. 319 с.

12. Рождественская Н. А. Способы межличностного познания: психолого-педагогический аспект. М.: ПЕР СЭ-Пресс, 2004. 282 с.

13. Моросанова В. И., Фомина Т. Г., Ованесбекова М. Л. Возрастная специфика взаимосвязи осознанной саморегуляции, академической мотивации и личностных особенностей учащихся // Теоретическая и экспериментальная психология. 2017. Т. 10, № 3. С. 34-45.

14. Прохоров А. О. Саморегуляция психических состояний: феноменология, механизмы, закономерности. М.: ПЕР СЭ, 2005. 352 с.

15. Осницкий А. К. Психологические механизмы самостоятельности. М.; Обнинск: ИГ-СОЦИН, 2010. 232 с.

16. Королева Ю. А. Социально-психологическая компетентность и жизнеспособность лиц с отклонениями в развитии: факторный анализ // Специальное образование. 2015. № 4 (40). С. 43-51.

17. Инденбаум Е. Л. Об информативности опросников в диагностике личности детей и подростков с легкими формами интеллектуальной недостаточности (Сообщение 2) // Дефектология. 2013. № 5. С. 3-13.

18. Ясвин В. А. Образовательная среда: от моделирования к проектированию. М.: Смысл, 2001. 365 с.

19. Серкин В. П. Алгоритм разработки и бланки специализированных семантических дифференциалов для оценки работы, профессии и профессионала // Психологическая диагностика. 2007. № 5. С. 11-29.

20. Proskurniak O. Diagnostic Methodology of Communicative Activity Development Levels in Adolescents With Mental Retardation // Science and Education, 2017, Issue 3. P. 90-96. DOI: 10.24195/2414-4665-2017-3-17

21. Хлыстова Е. В. Развитие перцептивной чувствительности у подростков с интеллектуальной недостаточностью // Специальное образование. 2009. № 2 (14). C. 50-59. 
22. Садыкова Г. Р. Проблема идентификации эмоций подростками с интеллектуальными нарушениями // Научно-методический электронный журнал «Концепт». 2014. № 6. C. 111-115. URL: http://e-koncept. ru/2014/14159.htm (дата обращения: 30.10.2018).

23. Бажукова О. А. Коррекция дезадаптивного поведения подростков с интеллектуальной недостаточностью: дисс. ... канд. психол. наук. Махачкала, 2006. 218 с.

24. Маллаев Д. М., Омарова П. О., Бажукова О. А. Психология общения и поведения умственно отсталого школьника: монография. СПб.: Речь, 2009. 159 c.

25. Gresham F. M., MacMillan D. L. Social Competence and Affective Characteristics of Students With Mild Disabilities // Review of Educational Research. 1997. Vol. 67, Issue 4. P. 377-415. DOI: 10.3102/00346543067004377

26. Королева Ю. А., Матасов Ю. Т. Взаимосвязь социально-психологической компетентности и жизнеспособности подростков с интеллектуальным недоразвитием // Вестник Челябинского государственного педагогического университета. 2015. № 10. С. 128-133.

27. Бажукова О.А. Девиантное поведение умственно отсталых подростков как предмет психологического исследования // Известия Российского государственного педагогического университета им. А. И. Герцена. 2006. T. 3, № 20. С. 89-92.

28. Печерский В. Г. Интраиндивидуальный контекст межличностного взаимодействия подростков и юношества с психическим недоразвитием // Вестник ТГУ. 2008. Вып. 5 (61). С. 354-362.

29. Назаревич О. С. Психологические особенности взаимосвязи формирования личностной самооценки и интеграции в социум у учащихся с умственной отсталостью: дисс. ... канд. психол. наук. Н. Новгород, 2004. 234 с.

30. Смирнова С. И. Особенности самооценки у детей и подростков с отклонениями развития в исследованиях по специальной психологии // Вестник Вятского государственного гуманитарного университета. 2009. № 2 (1). С. 131-135.

\section{References}

1. Kalinina N. V. Psikhologicheskoe soprovozhdenie razvitiya sotsial'noi kompetentnosti shkol'nikov [Psychological support for the development of students' social competence]. Diss. Dr. Sci. (Psych.). Samara, 2006. 460 p.

2. Marasanov G. I., Rototaeva N. A. Sotsial'naya kompetentnost': psikhologicheskie usloviya razvitiya v yunosheskom vozraste [Social competence: Psychological conditions for development in adolescence]. Moscow, Kogito-Tsentr Publ., 2003. $171 \mathrm{p}$. 
3. Linden M., Hautzinger M. Verhaltenstherapiemanual: Techniken, Einzelverfahren und Behandlungsanleitungen. Springer-Verlag Berlin Heidelberg, 2000. 536 s. DOI: $10.1007 / 978-3-662-10777-5$

4. Fetro J. V., Rhodes D. L., Hey D. W. Perceived personal and social competence: Development of valid and reliable measures. The Health Educator, 2010, V.42, no. 1, pp. 19-26. URL: https://digitalcommons.calpoly.edu/cgi/viewcontent. cgi?article=1045\&context=kine fac (Accessed 29 September 2018).

5. Hutchby I., Moran-Ellis J. (eds.) Children and social competence: Arenas of Action. London, Washington, D.C., Falmer Press, 1998. 245 p.

6. Singh G. Social competence of adolescents in relation to emotional intelligence and home environment. International Journal of Science and Research (IJSR), 2015, V. 4, Issue 9, pp. 649-651.

7. Belyaeva T. B. Model of social competence. Vestnik Novgorodskogo gosudarstvennogo universiteta. Seriya:Psikhologiya. Pedagogika. Sotsiologiya - Vestnik of Novgorod State University: Series: Psychology, Pedagogy, and Sociology, 2005, no. 31, pp. 8-12 (in Russian).

8. Kunitsyna V. N., Kazarinova N. V., Pogol'sha V. M. Mezhlichnostnoe obshchenie [Interpersonal communication]. St. Petersburg, Piter Publ., 2001. $544 \mathrm{p}$.

9. Vachkov I. V. Poly-subject interaction in the educational environment. Psikhologiya. Zhurnal Vysshei shkoly ekonomiki - Psychology: Journal of the Higher School of Economics, 2014, V. 11, no. 2, pp. 36-50 (in Russian).

10. Koroleva Yu. A. The role of social needs in the development of sociopsychological competence in adolescents with developmental disabilities. Defektologiya - Defectology, 2016, no. 3, pp. 26-36 (in Russian).

11. Remschmidt H. Adolescence and early adulthood: Problems of personality formation (Russ. ed.: Remshmidt Kh., T. A. Gudkova (ed.) Podrostkovyi iyunosheskii vozrast: Problemy stanovleniya lichnosti. Moscow, Mir Publ., 1994. 319 p.).

12. Rozhdestvenskaya N. A. Sposoby mezhlichnostnogo poznaniya:psikhologopedagogicheskii aspekt [Types of interpersonal cognition: A psycho-pedagogical perspective]. Moscow, PER SE-Press Publ., 2004. 282 p.

13. Morosanova V. I., Fomina T. G., Ovanesbekova M. L. Age characteristics of the relationships among conscious self-regulation, academic motivation, and personal traits of schoolchildren. Teoreticheskaya i eksperimental'naya psikhologiya - Theoretical and Experimental Psychology, 2017, V. 10, no. 3, pp. 34-45 (in Russian).

14. Prokhorov A. O. Samoregulyatsiya psikhicheskikh sostoyanii: fenomenologiya, mekhanizmy, zakonomernosti [Self-regulation of mental states: phenomenology, mechanisms, and regularity patterns]. Moscow, PER SE Publ., 2005. $352 \mathrm{p}$. 
15. Osnitskii A. K. Psikhologicheskie mekhanizmy samostoyatel'nosti [Psychological mechanisms of independence]. Moscow; Obninsk, IG-SOTsIN Publ., 2010. 232 p.

16. Koroleva Yu. A. Socio-psychological competence and vitality in individuals with developmental disabilities: Factor analysis. Spetsial'noe obrazovanie Special Education, 2015, no. 4 (40), pp. 43-51 (in Russian).

17. Indenbaum E. L. Informativeness of inventories in the diagnosis of personality of children and adolescents with mild intellectual disabilities (Report 2). Defektologiya - Defectology, 2013, no. 5, pp. 3-13 (in Russian).

18. Yasvin V. A. Obrazovatel'naya sreda: ot modelirovaniya k proektirovaniyu [Educational environment: From modeling to engineering]. Moscow, Smysl Publ., 2001. 365 p.

19. Serkin V. P. Algorithm for working out and forms of specialized semantic differential for assessing work, profession, and professionals. Psikhologicheskaya diagnostika - Psychological Diagnostics, 2007, no. 5, pp. 11-29 (in Russian).

20. Proskurniak O. Diagnostic methodology of communicative activity development levels in adolescents with mental retardation. Science and Education, 2017, Issue 3, pp. 90-96. DOI: 10.24195/2414-4665-2017-3-17

21. Khlystova E. V. Development of perceptual sensitivity in adolescents with intellectual disabilities. Spetsial'noe obrazovanie - Special Education, 2009, no. 2 (14), pp. 50-59 (in Russian).

22. Sadykova G. R. The problem of identification of emotions by adolescents with intellectual disabilities. Koncept: Scientific and Methodological e-magazine, 2014, no. 6, pp. 111-115. Available at: http://e-koncept.ru/2014/14159.htm (Accessed 30 October 2018).

23. Bazhukova O. A. Korrektsiya dezadaptivnogo povedeniya podrostkov s intellektual'noi nedostatochnost'yu [Correction of maladaptive behaviour in adolescents with intellectual disabilities]. Diss. Cand. Sci. (Psych.). Makhachkala, 2006. 218 p.

24. Mallaev D. M., Omarova P. O., Bazhukova O. A. Psikhologiya obshcheniya i povedeniya umstvenno otstalogo shkol'nika [Psychology of communication and behavior of mentally retarded schoolchildren]. St. Petersburg, Rech' Publ., 2009. 159 p.

25. Gresham F. M., MacMillan D. L. Social competence and affective characteristics of students with mild disabilities. Review of Educational Research, 1997, V.67, Issue 4, pp. 377-415. DOI: 10.3102/00346543067004377

26. Koroleva Yu. A., Matasov Yu. T. The relationship between socio-psychological competence and resilience in adolescents with intellectual disabilities. Vestnik Chelyabinskogo gosudarstvennogo pedagogicheskogo universiteta - Herald of Chelyabinsk State Pedagogical University, 2015, no. 10, pp. 128-133 (in Russian). 
27. Bazhukova O. A. Deviant behavior of mentally retarded adolescents as a subject of psychological research. Izvestiya Rossiiskogo gosudarstvennogo pedagogicheskogo universiteta im. A. I. Gertsena - Izvestia: Herzen University Journal of Humanities \& Science, 2006, V. 3, no. 20, pp. 89-92 (in Russian).

28. Pecherskii V. G. Intraindividual context of interpersonal interaction of adolescents and youths with mental retardation. Vestnik TGU - Vestnik TSU, 2008, V. 5 (61), pp. 354-362 (in Russian).

29. Nazarevich O. S. Psikhologicheskie osobennosti vzaimosvyazi formirovaniya lichnostnoi samootsenki i integratsii v sotsium u uchashchikhsya s umstvennoi otstalost'yu [Psychological features of the relationship between self-appraisal and integration into society in schoolchildren with mental retardation]. Diss. Cand. Sci. (Psych.). N. Novgorod, 2004. 234 p.

30. Smirnova S. I. Characteristics of self-appraisal in children and adolescents with developmental disabilities in special education researches. Vestnik Vyatskogo gosudarstvennogo gumanitarnogo universiteta - Bulletin of Vyatka State Humanities University, 2009, no. 2 (1), pp. 131-135 (in Russian). 